\title{
RAPID ASSAY DEVELOPMENT OF DICLOFENAC SODIUM COATED TABLET ASSAY USING FTIR COMPARED TO HPLC METHOD
}

\author{
ILMA NUGRAHANI', NOVENSIUS DILLEN' ${ }^{1}$ \\ 1School of Pharmacy, Bandung Institute of Technology, Indonesia \\ Email: ilma_nugrahani@fa.itb.ac.id
}

Received: 06 Mar 2018, Revised and Accepted: 13 Apr 2018

\begin{abstract}
Objective: A lot of coated tablet preparations of diclofenac have been marketed. This research aimed to develop and validate a quantitative analysis method for diclofenac sodium coated tablet using Fourier Transform Infrared (FTIR), which never reported.

Methods: The quantification was done by measuring the sample spectra, which then was converted into its derivative. Areas under the curve (AUC) of the derivative spectrums were plotted against the concentrations; corresponding to the calibration graphic. Then, the validation method was carried out by evaluating the accuracy, precision, linearity, range, limit of detection (LOD), and limit of quantification (LOQ).

Results: The results showed that diclofenac sodium had a specific peak within the wavenumber range of $1550-1605 \mathrm{~cm}^{-1}$. This area showed linearity to concentration within the range $0.1-1.0 \% \mathrm{w} / \mathrm{w}$, with coefficient correlation of 0.9998 . Recovery was found within $98-102 \%$ w/w. The intra and inter-day precision showed a coefficient of variance below 2\%. The LOD and LOQ were $0.0127 \%$ and $0.0424 \%$ respectively. Further, a comparative study was performed, between this method and the compendia method using HPLC. The results showed that the measurement method using FTIR has an advantage in terms of time and cost.
\end{abstract}

Conclusion: Based on all data, it is concluded that FTIR can be used as a valid alternative method. It is faster and more cost-effective for diclofenac sodium coated tablet content determination, compared to the compendia method.

Keywords: Assay, Comparative study, Diclofenac sodium, FTIR, HPLC

(C) 2018 The Authors. Published by Innovare Academic Sciences Pvt Ltd. This is an open access article under the CC BY license (http://creativecommons.org/licenses/by/4.0/) DOI: http://dx.doi.org/10.22159/ijap.2018v10i4.25682

\section{INTRODUCTION}

Methods for active compound analysis have developed rapidly, especially since the invention of various analytical instruments such as HPLC and gas chromatography. The development of quantitative analysis is driven by the need of more rapid, accurate and simple method of analysis. On the other side, the efficiency of cost should be considered; beside the realized of green pharmacy which is strong issued and recommended to be supported [1-3]. One of the developing methods prospectively is the determination level of an active substance by using FTIR instrument due to its free solvent usage. FTIR method has been developed and reported as a method of quantitative analysis for some active substances [4-7]. This method was explained to offer some advantages, such as simple sample preparation and minimum usage of organic solvents.

Diclofenac sodium is a nonsteroidal anti-inflammation drug (NSAID) with a mechanism of action inhibiting the cyclooxygenase enzyme, causing decreasing of prostaglandin synthesis [8,9]. For some purposes, the diclofenac tablets are formulated in the coated form, such as for extended release or protect from degradation [10-15]. Film coating of tablets and other solid dosage also formulated to mask the unpleasant taste and odours. Furthermore, coated tablet is produced to improve the appearance of dosage forms; for ease of swallowing; to achieve colonic drug delivery and controlled drug delivery, among others. Many excipient are added to be the coating materials for pharmaceutical products [10-15].

Assay method for diclofenac sodium coated tablet preparation in the compendia is by using HPLC $[8,9,16]$. Some developments also have been reported to improve the performance [17-19]. One of the difficulties in the coated-dosage form analysis is the matrix's separation. In the common analysis, the matrices are extraction by appropriate solvents, if needed also supported by other steps of chromatography. In some practical cases, the coating excipient is not separated. It will increase the viscosity of the analyte solution. Then, that causes troubles of the instrument. Besides, prolongs the time consumption. Another method which has reported to quantify diclofenac is spectro-photometry UV/visible
$[20,21]$, and voltammetry-GC [22]. However these methods also need solvent for extraction

In this study, FTIR instrument was proposed as a quantitative method for coated tablet of diclofenac sodium directly without extraction. Diclofenac sodium formula is $\mathrm{C}_{14} \mathrm{H}_{10} \mathrm{C}_{12} \mathrm{NNaO}_{2}$ with molecular weight of $318.129 \mathrm{~g} / \mathrm{mol}$. Diclofenac sodium structure as shown in fig. 1 has amine bond $(\mathrm{N}-\mathrm{H})$, carbonyl bond $(\mathrm{C}=0)$, and carbon double bond $(\mathrm{C}=\mathrm{C})$ which showing strong peaks in the IR spectrum $[8,9,16,23-25]$. These bonds are predicted to have a correlation with the quantity of the measured substance so that it is potentially used to determine diclofenac sodium content in a sample.<smiles>O=C(Cc1ccccc1Nc1c(Cl)cccc1Cl)O[Na]</smiles>

Fig. 1: Diclofenac sodium chemical structure

The purpose of this study was to develop a more rapid and simple assay method for diclofenac sodium in the coated tablet using FTIR directly. It means, without extraction and separation physically. Furthermore, the parameters of validation resulted would be compared with the trial obtained by method from the compendia, completely with a short cost analysis.

\section{MATERIALS AND METHODS}

\section{Material}

The materials used in this study were: standard of diclofenac sodium (PT Pharos), KBr crystals (IR-spectra grade), acetone (Brataco, Indonesia), aqua-bidestilata, methanol pro HPLC, phosphate buffer $\mathrm{pH} 2.5$, tablet matrix base, micropore $0.45 \mu \mathrm{m}$ filter paper, and diclofenac sodium coated tablet preparations as samples. 


\section{Apparatus}

The apparatus used in this study are: mortar, electronic scales, measuring glass, beaker glass, micro-pipette, FTIR (Jasco-4200 type A, Japan), KBr plate, pellet pressure tool (Jasco mini-press MP-1), mini-oven (Memmert), HPLC (Hitachi L-7000).

\section{Methods}

The study began with infrared spectrum analysis of diclofenac sodium in the range of $4000-400 \mathrm{~cm}^{-1}$ (mid-IR). From transmittance spectra, it was changed to absorption with the correlation: $A=-\log [T]$ [23-25]. Further, derivatization of the absorption spectrum was done; next the peak which clearest and can be used as the basis for making calibration curve was determined. The spectra selected must have the high value and specific to the analyte. Besides, it must not overlap with the other component's spectra within the sample. The most important is, it should be linear over the concentration. Peak that has fulfilled the criteria was used to plot the calibration curve. The method was then validated to state that the method used has been appropriate to determine the levels of the active substance used. Validation criteria evaluated include the parameters of accuracy, precision, linearity, specificity, range, LOD and LOQ [16, 26-31]. The validated analysis method was next used to determine the level of diclofenac in the coated tablet from the market. The result was then compared with the amount declared on the label of the packaging's preparation. This method is compared with methods that have been validated in the pharmacopoeia in terms of time, cost, and LOD/LOQ.

\section{Development of diclofenac sodium analysis method}

\section{Spectrum measurement}

Variations of standard concentrations of diclofenac sodium in KBR crystals were made in 10 different concentration within the range of $0.1-1 \% \mathrm{w} / \mathrm{w}$. The mixture was weighed for $10 \mathrm{mg}$, then put into $\mathrm{KBr}$ plate and compressed using a press device. The results were measured at wavenumbers $4000-400 \mathrm{~cm}^{-1}$ and repeated three times.

\section{Derivatization and standard wavenumber range determination}

Derivatization was performed to increase the separation between the peaks, as same as the other spectroscopy methods when some spectrums are overlapped [32-36]. The obtained transmittance spectrum was changed into absorption then was derivatized to facilitate appropriate peak selection. The derivatization results from all concentrations were overlaid together. From the overlaid spectrum, peaks that have high molar absorption, specific, and linear to concentration was chosen. The peak which meets the criteria was then used as the base for plotting the calibration curve.

\section{Validation of analysis method}

Validation evaluation was conducted include parameter of accuracy, precision, linearity, specificity, range, LOQ, and LOD. The parameter's tests are based on guidance in the references [16, 26-31].

\section{Specificity}

The spectrum of the active substance, the matrices, the matrices added by the drug, and the sample were overlaid with each other. Range of wavenumbers where the peak present in the spectrum of the drug substance but not in the matrix spectrum was selected.

\section{Linearity}

A series concentration of standard diclofenac was prepared in $\mathrm{KBr}$ IR spectra-grade with concentrations of $0.1 \%$ to $1.0 \%$ of 10 units. Each concentration was measured using FTIR, then the spectrum was derivatized. The AUC value of the selected peak is measured. A curve between standard concentration and AUC value was plotted. The acceptance criterion for linearity is the correlation coefficient $\geq$ 0.999 and coefficient of variance for regression function $\leq 2 \%$.

\section{Range}

The concentration range was used for the test of accuracy, precision, and linearity.

\section{Accuracy}

The test was done using standard addition method. One-sample tablet was grounded as blank. It is then added in a series of diclofenac sodium standard with the amount of $80 \%, 100 \%$, and $120 \%$, respectively. Diclofenac sodium $100 \%$ is equivalent to $50 \mathrm{mg}$ of diclofenac sodium standard. The standards were then sampled and ground together with $\mathrm{KBr}$ IR spectra-grade with a ratio of 1:100. Each concentration was measured using FTIR and derivatized. The AUC value of the selected peak was measured, then the measured value content of each standard is determined using the calibration curve. Accuracy criteria are accepted if the recovered values of these three concentrations are within the range of $98-102 \%$.

\section{Precision}

Determination used standard addition method. One sample tablet was ground as blank, after that added to the blanket of a $100 \%$ diclofenac sodium standard equivalent to $50 \mathrm{mg}$ of diclofenac sodium. Standard was then sampled and ground together with $\mathrm{KBr} I \mathrm{IR}$ spectra-grade with a ratio of 1: 100 . The mixture was measured using FTIR six times on the same day (intra-day precision) and repeated on three different days (inter-day precision). The AUC value of the selected peak was measured, then the measured value content of each standard was determined using the calibration curve. Precision criteria are accepted if the coefficient of variance value $\leq 2 \%$.

\section{LOD and LOQ}

Value of LOD and LOQ could be determined using following equation [31]:

$$
\mathrm{LOD}=\frac{3 \mathrm{~S}_{\mathrm{y} / \mathrm{x}}}{\mathrm{b}} \mathrm{LOQ}=\frac{10 \mathrm{~S}_{\mathrm{y} / \mathrm{x}}}{\mathrm{b}} \text { with } S_{y / x}=\sqrt{\frac{\sum(y i-\hat{y} i)^{2}}{n-2}}
$$

\section{Determination of diclofenac sodium levels using FTIR}

Ten of sample tablets were taken. Each was weighed, and the average was calculated. All the tablets were ground until homogeneous, next mixed in $\mathrm{KBr}$ crystal with concentration of $1 \%$ $\mathrm{w} / \mathrm{w}$. The levels of the active substances in the sample were measured using the calibration curve that had been made. The result of the determination of the content was then compared with the content declared on the packaging.

\section{Determination of diclofenac sodium levels using HPLC}

The method of diclofenac sodium content assay was adopted from the method written in the British Pharmacopoeia 2013 [9].

\author{
Chromatography system \\ Details of chromatographic system used in the experiment \\ Mobile phase: phosphate buffer pH 2.5: Methanol (20:80) \\ Stationary phase: C8 column $\emptyset 3 \mathrm{~mm}$ length $15 \mathrm{~cm}$ \\ Flow rate: $0.5 \mathrm{ml} / \mathrm{min}$ \\ Detector: UV lamp $254 \mathrm{~nm}$ \\ Vol. of sample: $20 \mu \mathrm{l}$
}

\section{Calibration curve plotting}

Standard series of diclofenac sodium concentration was prepared in the mobile phase with concentrations of $10,25,50,75$, and $100 \mathrm{ppm}$, respectively. Each concentration was measured using HPLC, then the retention time and AUC values of each concentration were recorded. The curve between concentrations with AUC values was plotted to obtain standard calibration curve.

\section{Measurement of coated tablet samples using HPLC}

Ten of coated tablets as the sample were taken and crushed, then weighed amount of powder equivalent to $50 \mathrm{mg}$ diclofenac sodium. The powder was dissolved in $70 \mathrm{ml}$ pro-HPLC methanol, next filled with mobile phase up to $100 \mathrm{ml}$. The solution was then filtered and measured using HPLC. The AUC value of the diclofenac sodium peak was measured and used to determine the level of the active substance in the sample [9].

\section{RESULTS AND DISCUSSION}

\section{Development of diclofenac sodium assay method}

Firstly, the transmittance of infrared which pass the sample was recorded. Quantitative analysis of component in a sample can be 
measured using FTIR if there is a specific and suitable peak in the spectrum of the target component. The peaks selected for analysis should have high molar absorption. Furthermore, it does not overlap with other peaks of other components within the sample, symmetrical, and have linear correlation between absorbance and concentration. The absorption data was calculated automatically from transmittance by the instrument with the formula [23-25]:

$\mathrm{A}=-\log \mathrm{T}[\mathrm{]}]$

$\mathrm{A}=$ Absorbance $\mathrm{T}=$ Transmittance

Measurement of levels using FTIR is based on Beer-Lambert's law, which says that the absorbance value of a light as it passes through the sample will be directly proportional to the thickness and concentration of the sample [23-25].

$\mathrm{A}=\varepsilon \mathrm{cl}$

$\mathrm{A}=$ absorbance $\mathrm{c}=$ concentration

$\varepsilon=$ molar absorptivity $\mathrm{l}=$ thickness
In Beer-Lambert's law, the plot curve between absorbance and concentration must be linear against ' $\varepsilon l^{\prime}$ gradient and will pass through the origin point. Theoretically, to analyze an unknown component sample, some standard solutions with known concentrations need to be prepared, suitable peaks are selected, the absorption at the peak wave number is measured, and the calibration curve is plotted. The concentration of the sample component can then be determined using the sample absorbance value and the calibration curve that has been made [25].

So practically, the development of the method was begun with determining the peak that can be used as a standard for the assay. First, standard spectrum measurements were performed at concentrations of 0.1 to $1 \%$. The obtained transmittance spectrum was then converted to absorbance, which next was derived to determine the corresponding peak as the base for plotting calibration curve $[32,33]$. From the overlaid spectrum as shown in fig. 2 below, it is found that peaks in the range of $1550-1605 \mathrm{~cm}^{-1}$ tend to be linear. This peak corresponds to the stretching of the $\mathrm{C}=$ O bond [23-25].

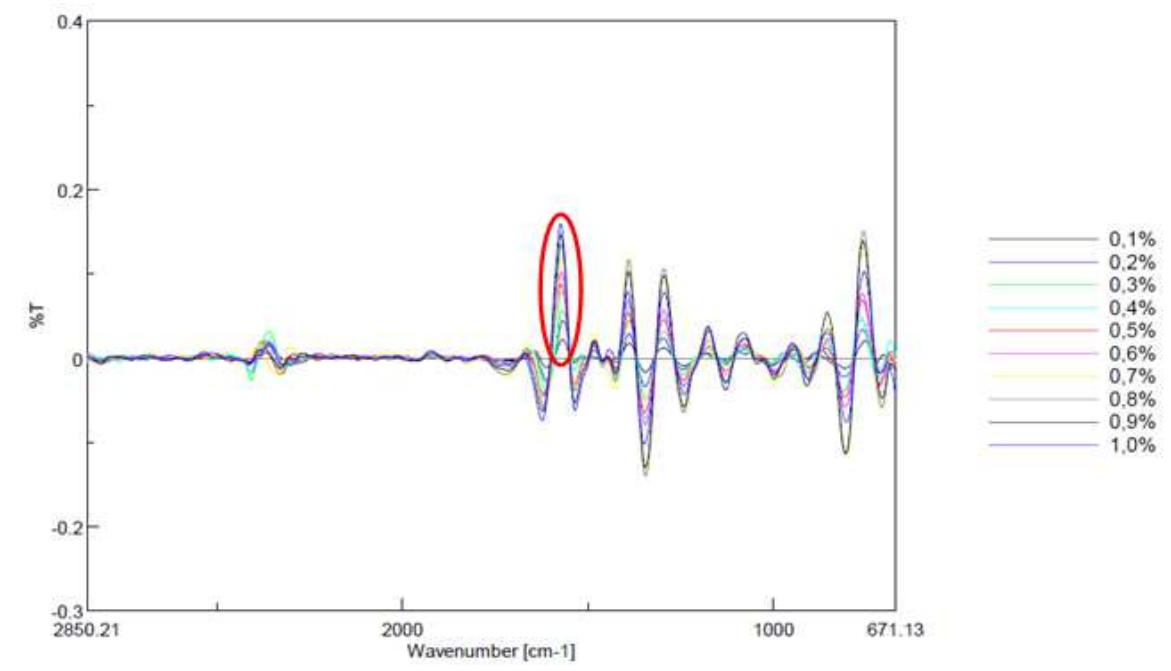

Fig. 2: Overlay of derivative absorbance of standard spectrum of diclofenac sodium in concentration $0.1 \%$ to $1 \%$ w/w

\section{FTIR assay method validation}

\section{Specificity}

In the specificity test, spectrums of active substances, matrix, samples, and samples-added matrix were measured. This test aims to determine whether there is any disturbance caused by the matrix component of the sample. The spectrum resulted is not disturbed by the matrix (fig. 3).
Spectrums of the coated tablets and the uncoated tablets were measured. They were compared to determine whether the coating agent had effect or not on the diclofenac sodium spectrum.

From the overlay result as displayed in fig. 4 , the spectrum of coated tablets and the spectrum of uncoated tablets did not have significant differences. So it explains that the coating agent did not affect the spectrum of the whole component of tablet.

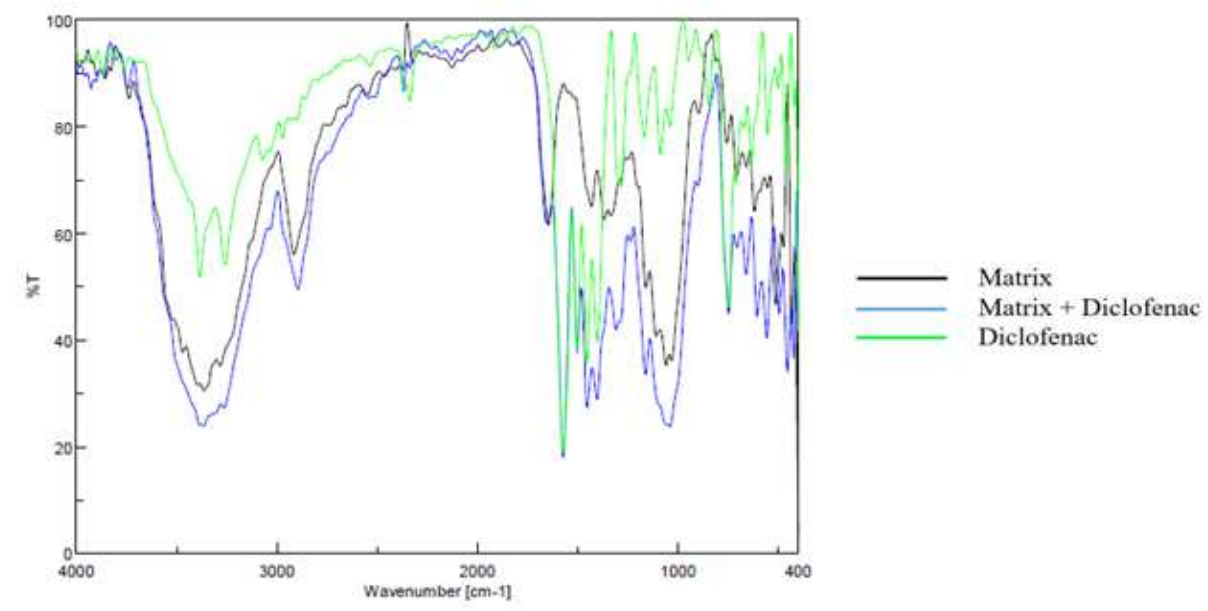

Fig. 3: Overlay of spectrums of active substances, matrix, and samples-added matrix 


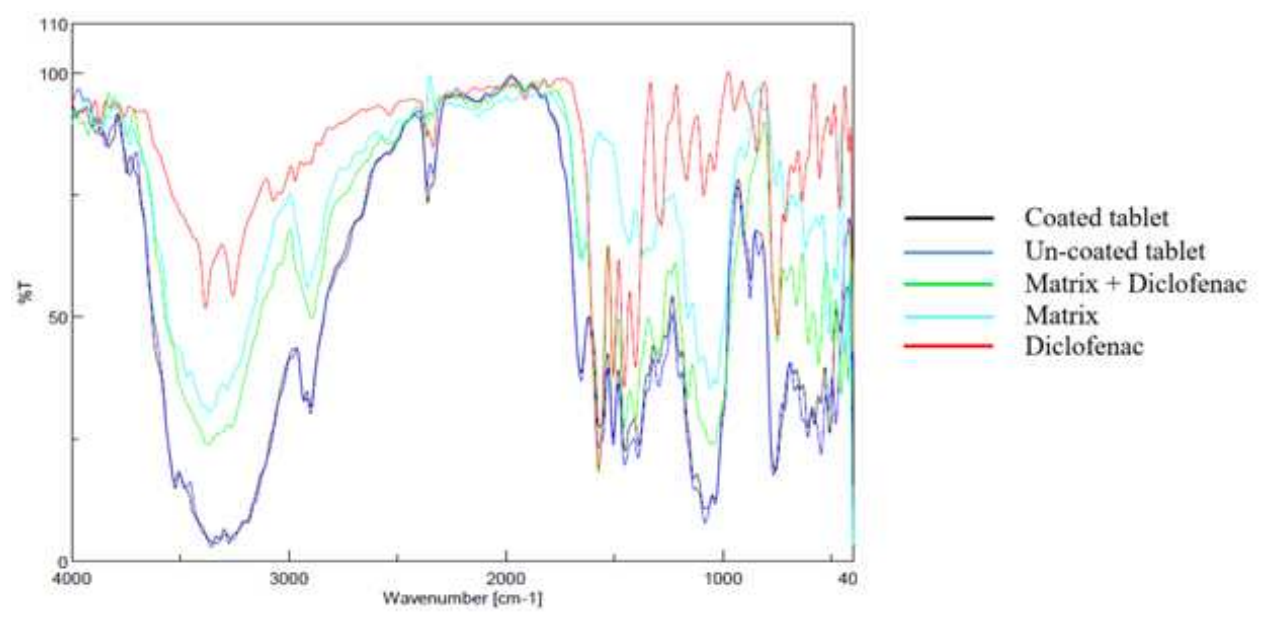

Fig. 4: Overlay of transmittance spectrum between the coated tablet sample with un-coated tablet, sodium diclofenac bulk, and the mixture of sodium diclofenac with matrix

\section{Linearity}

Linearity is the ability of an analytical method to obtain measurements that are directly proportional to the concentration or number of analyte in a sample at a given range [26-31]. Linearity testing includes standard measurements of each concentration three times with re-sampling in every measurement. The measurement results are shown in table 1.

Table 1: Diclofenac sodium calibration curve data using derivative absorbance

\begin{tabular}{|c|c|c|c|c|}
\hline \multirow[t]{2}{*}{ Concentration (\%) } & \multicolumn{3}{|c|}{ AUC $(n=3)$} & \multirow[t]{2}{*}{ Average* } \\
\hline & 1 & 2 & 3 & \\
\hline 0.1 & 0.56577 & 0.51979 & 0.54471 & $0.54342 \pm 0.02302$ \\
\hline 0.2 & 1.07567 & 0.99456 & 1.01292 & $1.02772 \pm 0.04253$ \\
\hline 0.3 & 1.47897 & 1.48985 & 1.53707 & $1.50196 \pm 0.03089$ \\
\hline 0.4 & 2.03299 & 2.03112 & 2.01511 & $2.02641 \pm 0.00983$ \\
\hline 0.5 & 2.48560 & 2.57541 & 2.69375 & $2.58492 \pm 0.10440$ \\
\hline 0.6 & 3.07040 & 3.05048 & 3.04385 & $3.05491 \pm 0.01382$ \\
\hline 0.7 & 3.58413 & 3.57315 & 3.56369 & $3.57366 \pm 0.01023$ \\
\hline 0.8 & 4.07479 & 4.06845 & 4.09385 & $4.07903 \pm 0.01322$ \\
\hline 0.9 & 4.59470 & 4.58005 & 4.59168 & $4.58881 \pm 0.00774$ \\
\hline 1.0 & 5.13440 & 5.09514 & 5.14792 & $5.12582 \pm 0.02742$ \\
\hline
\end{tabular}

Note: AUC: area under the curve of absorbance, *All values are reported as mean $\pm \mathrm{SD}(\mathrm{n}=3)$

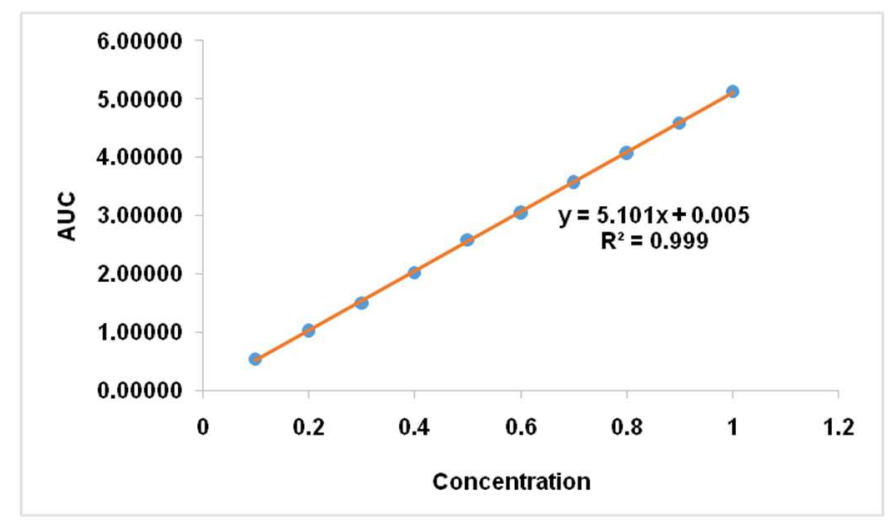

Fig. 5: Diclofenac sodium calibration curve

From test, a linear regression equation of diclofenac sodium was obtained (fig. 5). The regression equation was $y=5.101 x+0.0051$ with a correlation coefficient value equaled to 0.9998 and coefficient variance of regression function were $0.772 \%$. It was concluded that the method has met the linearity criteria in the concentration range of $0.1 \%$ to $1 \% \mathrm{w} / \mathrm{w}$.

\section{Accuracy}

Accuracy expresses the proximity between the value obtained from the measured result to the reference value or the real value [26-31]. Accuracy testing was done by standard addition method. The measurement results are shown in table 2 . 
Table 2: Diclofenac sodium accuracy test data

\begin{tabular}{|c|c|c|c|c|}
\hline Added concentration & AUC value & Average of AUC value* & AUC value theoretically & \%Recovery \\
\hline $80 \%$ & $\begin{array}{l}2.3685 \\
2.3370 \\
2.3684 \\
2.3420 \\
2.3355 \\
2.3518\end{array}$ & $2.3505 \pm 0.0064$ & 2.3435 & $99.54 \%$ \\
\hline $100 \%$ & $\begin{array}{l}2.6050 \\
2.5811 \\
2.5963 \\
2.6126 \\
2.6248 \\
2.5975\end{array}$ & $2.6028 \pm 0.0058$ & 2.5985 & $99.69 \%$ \\
\hline $120 \%$ & $\begin{array}{l}2.8653 \\
2.8444 \\
2.8454 \\
2.8364 \\
2.8746 \\
2.8329\end{array}$ & $2.8498 \pm 0.0058$ & 2.8536 & $99.09 \%$ \\
\hline
\end{tabular}

Note: AUC: area under the curve of absorbance spectrum, $*$ All values are reported as mean \pm CV $(n=6)$

From the results of accuracy testing at three concentrations shown in table 2, the method has met the accuracy criteria because it has a recovery value between $98-102 \%$.

\section{Precision}

Precision in the analytical method states the proximity of the obtained results (degree of scatter) from several sample measurements of a homogeneous sample under certain conditions [26-31]. Precision testing was performed using a standard method of addition with a measurement of six times. The precision level of the analytical method is determined by the value of the coefficient variance. There are two precision level tested: intra-day precision and inter-day precision.

Intra-day precision states the rate of repeatability of results under the same conditions of work within a narrow time span while inter-day precision states the rate of repeatability of results under various working conditions, such as different days or equipments.

Table 3: Diclofenac sodium precision test results

\begin{tabular}{llll}
\hline & AUCs of day 1 & AUCs of day 2 & AUCs of day 3 \\
\hline & 2.60499 & 2.61607 & 2.59175 \\
& 2.58106 & 2.60909 & 2.60347 \\
& 2.59627 & 2.59752 & 2.61566 \\
& 2.61255 & 2.60807 & 2.61947 \\
& 2.62478 & 2.60544 & 2.61095 \\
Average & 2.59752 & 2.59412 & 2.60754 \\
CV & 2.60286 & 2.60505 & $0.38296 \%$ \\
\hline
\end{tabular}

Note: AUC: area under the curve of absorbance spectrum; CV: coefficient variance

From the test results in table 3 , it was concluded that the quantification method of diclofenac sodium with FTIR has met the criteria of intra-day and inter-day precision. The value of coefficient variance from six times consecutive measurement on the same day and on three different days were below $2 \%$.

\section{Range}

The range is the interval between the lowest concentration and the highest concentration of the analyte in the sample which having sufficient valid parameters. The range values used generally estimated from $80 \%$ to $120 \%$ of the concentration value of the test compound. In this study, the concentration range of diclofenac sodium from $0.1 \%$ to $1.0 \%$ has met the parameters of accuracy, precision, and linearity [26-31].

\section{LOD and LOQ}

LOD is the lowest value that can be measured by a method of analysis without any certainty of the accuracy and precision of the value obtained. LOQ is the smallest quantity that can be accurately and precisely measured by an analytical method [26-31]. In the validation of this method, an equation was used to determine the value of LOD and LOQ. LOD was obtained at $0.0127 \% \mathrm{w} / \mathrm{w}$, meanwhile the LOQ at $0.0424 \% \mathrm{w} / \mathrm{w}$.

\section{Tablet sample testing}

The method assay by FTIR which has been validated, then used to measure the sample content of the coated tablets on the market. The sample was measured six times. Next the diclofenac sodium content was determined using the previously obtained regression equation from the calibration curve.

From the assay results in table 4, the sample of diclofenac sodium coated tablets met the criteria of the pharmacopoeia requirement. It states the range 95 to $105 \%$ of the levels declared in the packaging.

\section{Diclofenac sodium testing using HPLC}

The coated tablet commonly needs a lot of solvents and many steps of extraction to separate the analyte from its matrices more than uncoated preparation. The excipients can include glidants (flow aids), diluents, binders or granulating agents and lubricants to ensure efficient compressing; disintegrants to promote tablet break-up in the digestive tract. Moreover, the sweeteners or flavours are added to enhance the taste; meanwhile, pigments to make the tablets visually attractive [1015]. Therefore, chromatography is usually used for assay to overcome the trouble of matrices influence $[16,17]$. HPLC is the method to diclofenac sodium tablet assay in USP, British 
Pharmacopoeia and Indonesian Pharmacopoeia $V[8,9,16]$. In this study; the assay method using was adopted from British
Pharmacopeia. This step was in order to compare compendia method with the developed method.

Table 4: Sample testing results using FTIR assay method

\begin{tabular}{lll}
\hline AUC value & Measured content in KBr mixture (mg) & Measured content in each tablet (mg) \\
\hline 1.3375 & 0.2612 & 50.1511 \\
1.3405 & 0.2617 & 50.2644 \\
1.3326 & 0.2602 & 49.9685 \\
1.3305 & 0.2598 & 49.8902 \\
1.3263 & 0.2590 & 49.7321 \\
1.3289 & 0.2595 & 49.8274 \\
& Average* & $49.9723 \pm 0.2013$ \\
& Declared content & $50 \mathrm{mg} / \mathrm{tablet}$ \\
\end{tabular}

*All values are reported as mean $\pm \mathrm{SD}(\mathrm{n}=6)$

Table 5: Diclofenac sodium calibration curve data using HPLC

\begin{tabular}{lllll}
\hline Concentration (ppm) & AUC & \multicolumn{2}{c}{ Average* } & \multicolumn{2}{c}{} \\
\cline { 2 - 5 } & $\mathbf{1}$ & $\mathbf{2}$ & 510084 & $510081.00 \pm 491.5069$ \\
10 & 510571 & 509588 & 1306301 & $1299459.33 \pm 6046.647$ \\
25 & 1294832 & 1297245 & 2676947 & $2673117.67 \pm 3316.418$ \\
50 & 2671175 & 2671231 & 4041067 & $4027417.33 \pm 12570.06$ \\
75 & 4016318 & 4024867 & 5335229 & $5323496.63 \pm 18703.82$ \\
100 & 5301927 & 5333334 & 6747041 & $6739305.33 \pm 17451.58$ \\
125 & 6719323 & 6751552 & & \\
\hline
\end{tabular}

*All values are reported as mean $\pm \mathrm{SD}(\mathrm{n}=3)$, The calibration curve was arranged based on data in table 5 , which is displayed in fig. 6 as follows:

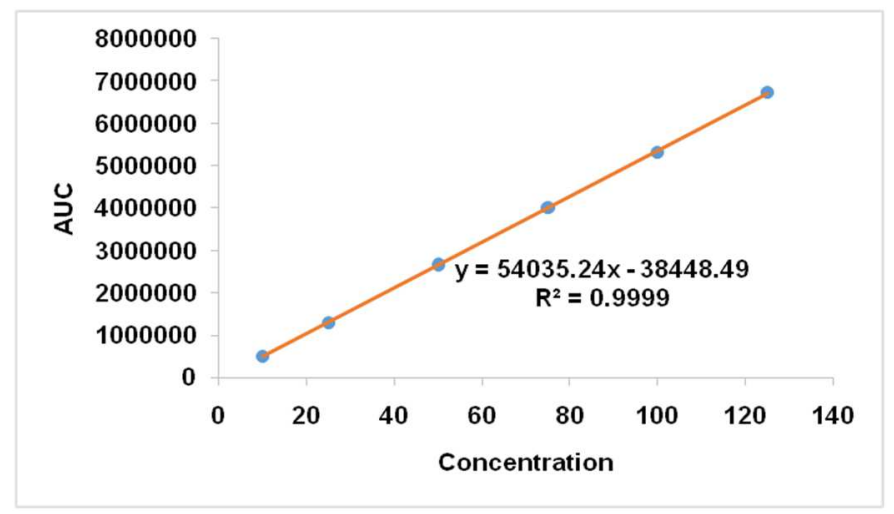

Fig. 6: Diclofenac sodium calibration curve using HPLC

Based on the curve in fig. 6, the LOD and LOQ was yielded the value LOD: $1.46 \mathrm{ppm}$ and LOQ: $4.88 \mathrm{ppm}$.
Furthermore, the coated tablets of sodium diclofenac found from the market, were determined their content using this established method. This experiment yielded the results as follows (table 6).

Table 6: Diclofenac sodium coated tablet sample testing results using HPLC

\begin{tabular}{lll}
\hline AUC value & Measured content (mg) & \% Recovery \\
\hline 2666366 & 50.06 & $100.11 \%$ \\
2685082 & 50.40 & $100.81 \%$ \\
2689407 & 50.48 & $100.97 \%$ \\
2693681 & 50.56 & $101.12 \%$ \\
2701469 & 50.71 & $101.41 \%$ \\
2701112 & 50.70 & $101.39 \%$ \\
& Average & $100.97 \%$ \\
& SD & $0.48 \%$ \\
\hline
\end{tabular}

The data shows that the branded sample coated tablet fulfilled the compendia requirement (BP: 95-102\% w/w) [9].

\section{Comparison of analysis methods}

After the method of diclofenac sodium assay using FTIR was validated, a comparison of this newly developed method to the method contained in the compendia was done. The comparable factors include the time required during the analysis, the cost required, as well as the detection capability of each method. The differences were listed in table 7,8 , and 9. Table 7 
explains time factor, meanwhile table 8 illustrates the cost, then table 10 is about the sensitivity which represented by LOD and LOQ.

\section{Time factor}

The result of time used calculation is listed in table VII.

Table 7: Comparison of FTIR with HPLC method in time factor

\begin{tabular}{lll}
\hline Compared factors & FTIR & HPLC \\
\hline & $1-2 \mathrm{~h}$ & $7-8 \mathrm{~h}$ \\
Preparation duration & Simpler sample and standard & $\begin{array}{l}\text { Longer preparation time because of the more } \\
\text { complex preparation procedure, such as the } \\
\text { mearation procedure, only including }\end{array}$ \\
mobile phase preparation & \pm 10 min per sample \\
\hline
\end{tabular}

In terms of time listed in table 7, FTIR has advantages over HPLC with shorter preparation duration and sample measurement duration. The preparation procedure for the analytical method using FTIR is simpler because it only includes mixing with $\mathrm{KBr}$ and pressing. Preparation for HPLC tends to be longer and complicated because it requires the preparation of a mobile phase with a particular composition. In addition, the duration of measurement using the FTIR instrument is much faster than that of the HPLC. The ease of preparation and short duration of the work process became the prominent points of the FTIR method.

\section{Cost factor}

The cost factor comparison is displayed in table 8 as follows.

Table 8: Comparison of FTIR method with HPLC method in cost factor

\begin{tabular}{|c|c|c|}
\hline \multicolumn{3}{|l|}{ FTIR } \\
\hline Material & Amount needed & Estimated cost \\
\hline KBr IR-spectra grade & $2 \mathrm{~g}$ & Rp 50.000,00 \\
\hline & Total & Rp 50.000,00 \\
\hline \multicolumn{3}{|l|}{ HPLC } \\
\hline Material & Amount needed & Estimated cost \\
\hline Aquadest & 11 & Rp 35.000,00 \\
\hline Methanol pro HPLC & 11 & Rp $150.000,00$ \\
\hline \multirow{2}{*}{$\begin{array}{l}\text { Etc. (ex: filter paper, } \\
\text { buffer solution material, micropipet tip) }\end{array}$} & - & Rp 20.000,00 \\
\hline & Total & Rp. $205.000,00$ \\
\hline
\end{tabular}

In terms of cost, the method of diclofenac sodium analysis using FTIR also has advantages with cheaper material prices. The analytical method with FTIR requires only $\mathrm{KBr}$ as a carrier material in the assay while HPLC method requires a relatively large volume of mobile phase for measuring the content level. In addition, the HPLC requires the column as a stationary phase which is expensive. The maintenance of HPLC instruments also requires a higher cost than
FTIR instruments in the long term. FTIR is concluded as a more economical method of analysis.

\section{LOD and LOQ}

The comparison of LOD and LOQ between the developed method with the British compendia's method (HPLC) is shown in table 10.

Table 10: Comparison of FTIR with HPLC method in detection capability

\begin{tabular}{lll}
\hline Factors & FTIR & HPLC \\
\hline LOD & $0.0127 \% /$ & $0.000146 \% /$ \\
& $127 \mathrm{ppm}$ & $1.46 \mathrm{ppm}$ \\
LOQ & $0.0424 \% /$ & $0.000448 \% /$ \\
& $424 \mathrm{ppm}$ & $4.48 \mathrm{ppm}$ \\
\hline
\end{tabular}

From detection capability's data as listed in table 10 above, HPLC showed the more adequate LOD and LOQ. It means; the sensitivity of FTIR method is about 1/100 times of HPLC. However, FTIR can measure the higher concentration than HPLC. This eminence is due to the limited range of measurements of each instrument. FTIR can detect analyte in solid samples within the range of 0.1 to $1.0 \%$ with plate thickness of 0.1-0.2 mm. HPLC has a measurement capability in lower concentration range of up to $1 \mathrm{ppm}$, but unable to give exact measurements at higher concentration, example at $1000 \mathrm{ppm}$.

Furthermore, all validation parameters have shown the equal values compared with other methods referred [17-22]. The main differences are the range and LOD/IOQ; which in average FTIR is about $1 / 100$ time lower to HPLC $[17,18]$. Other reported method is voltammetry and gas chromatography methods with LOD/1OQ were determined as 4.8 and $0.15 \mu \mathrm{g} / \mathrm{ml}$ for LSV and GC-MS, respectively [22]. So, the developed LSV and GC-MS yield the almost similar limit values to HPLC methods, then FTIR is less sensitive compared. However, FTIR almost equal to the spectrophotometry UV reported $[20,21]$, which shown the $\mathrm{LOQ}$ in the range $5-25 \mu \mathrm{g} / \mathrm{ml}$ of the spectrum at $270-282 \mathrm{~nm}$.

Considering the accuracy and precision, it proved that developed FTIR-AUC-derivative analysis is suitable to interchange with the other methods. The sensitivity also appropriate due to the dose of FTIR is match in the range to be quantified accurately. This instrument can produce the accurate and precision measurement for the distinctive dose of the active compound, by derivative and AUC calculation. The main advantage in this method is free of solvent. Besides, it shows the simplicity, less costly, and easy to conduct. Further, this method is proven more friendlier for the environment, support the green chemistry issue. Therefore, this method should be proposed as an economically alternative for content determination of the high-dose drug. As prediction, base on this result, is still appropriate for assay of an amount about $50 \mathrm{mg} /$ tablet directly. 


\section{CONCLUSION}

FTIR-AUC-derivative method is suitable to measure diclofenac sodium in the coated tablet matrix in the range of concentration 0.1 to $1.0 \% \mathrm{w} / \mathrm{w}$ with plate thickness of $0.1-0.2 \mathrm{~mm}$. The LOD and LOQ are $0.0127 \%$ and $0.0424 \% \mathrm{w} / \mathrm{w}$ respectively. This method was proven suitable to determine the active compound in the coated tablet preparations in the dose $50 \mathrm{mg}$. As comparison, FTIR has the advantage in terms of time and cost than compendia's HPLC method, but its sensitivity is lower.

\section{ACKNOWLEDGMENT}

This research was supported by Capacity Improvement Program, LPPM ITB, Bandung Institute of Technology, Indonesia. The authors would like to thank to PT Phapros Pharmaceutical Industry, Indonesia, for the diclofenac material support.

\section{AUTHORS CONTRIBUTIONS}

All the author have contributed equally

\section{CONFLICT OF INTERESTS}

Declared none

\section{REFERENCES}

1. Namies'nik J. Green analytical chemistry. J Separation Sci 200;24:151-3.

2. Rozera R, Khatik GL, Gupta V. Virtual Labs: Greener and economic approach for learning the Pharma-Lab. Int J Green Pharm 2017;11(4, Suppl 2):663-70.

3. International Pharmaceutical Federation. FIP STATEMENT OF POLICY Environmentally sustainable pharmacy practice: Green pharmacy. [Internet]. Buenos Aires, Argentina: FIP Bureau; 2016 [cited 2017 Sep 24]. Available from: http://www. fip. org/www/uploads/database_file. php?id=376andtable_id=.

4. Pandey S, Pandey P, Tiwari G, Tiwari R, Rai AK. FTIR spectroscopy: a tool for quantitative analysis of ciprofloxacin in tablets. Indian J Pharm Sci 2012;74:86-90.

5. Rakesh P, Charmi P, Rajesh P. Quantitative analytical applications of FTIR spectroscopy in pharmaceutical applied areas. J Adv Pharm Educ Res 2014;4:145-57.

6. Sahoo S, Chakraborti CK, Mishra SC, Nanda UN, Naik S. FTIR and XRD investigations of some fluoroquinolones. Int J Pharm Pharm Sci 2011;3:165-70.

7. Bhongade B, Talath S, Dhaneswar SA. Validated method for the quantitation of ciprofloxacin hydrochloride using diffuse reflectance infrared fourier transform spectroscopy. Inter J Spec 2014:1-4.

8. Ministry of Health of Republic of Indonesia. Pharmacopoeia Indonesia, 5th ed. Jakarta: Ministry of Health of Republic of Indonesia; 2014.

9. The British Pharmacopoeia Commission, British Pharmacopoeia 2013., [Internet] United Kingdom: The British Pharmacopoeia Commission; 2013 [cited 2017 Sep 24]. Available from: http://www. uspbpep. com/bp2013/data/5420. asp.

10. Hussan SD, S. Roychowdhury, P. Verma, V. Bhandari. A review on recent advances of enteric coating. IOSR J Pharm 2012;2:5-11.

11. Oforikwakye K, Adom ENN, Kipo SL. Preparation and in vitro characteristics of tablet cores coated with albizia, albizia/khaya and albizia/HPMC films. Int J App Pharm 2009;1:22-9.

12. Adedokun M, Nkata C. Optimized delivery of diclofenac sodium formulated in a sustained release Raphia Africana hydrocolloid matrix. Int J App Pharm 2018;10:109-14.

13. Sundari PT, Gaud RS. Formulation and evaluation of alcohol resistant dosage forms of diclofenac sodium. Int J Pharm Pharm Sci 2013;5:854-7.

14. Ahmeda SI, Mangamoorib LN, Raoc YM. Formulation and characterization of matrix and triplelayer matrix tablets for oral controlled drug delivery. Int J Pharm Pharm Sci 2010;2:137-43.

15. Nawle RB, Tadvee AA. Formulation and evaluation of time-release compression coated tablet containing acebrophylline for chronotherapy of asthma. Int J Pharm Pharm Sci 2014;6:231-7.

16. United States Pharmacopeia (USP) 34 (NF 29), Chapter<621>, Edition 2011.

17. Atto AR. New method for determination of diclofenac sodium by High Performance Liquid Chromatography. Tikrit J Pharm Sci 2012;8:60-7.

18. Ahmed SM, Raparla LP, Omer M. RP-HPLC method development and validation for simultaneous estimation of diclofenac sodium and serratiopeptidase in tablet dosage form. Int J Res Pharm Nano Sci 2015;4:10-8.

19. Al-kamarany MA, Karbane ME, Belomaria M, Azougagh M, Hubert PH, Alanazi F, et al. Development and validation of LC method for the diclofenac sodium release determination using accuracy profile concept. Asian J Chem 2012;24:4393-400.

20. Mali A, Jadhav S, Mane P, Tamboli A. Development and validation of UV spectrophotometric estimation of diclofenac sodium bulk and tablet dosage form using area under curve method. PharmaTutor Mag 2015;3:21-5.

21. Naveed S. UV spectrophotometric assay of diclofenac sodium available brands. J Innovations Pharm Biol Sci 2014;1:92-6.

22. Yilmaz B, Ciltas U. Determination of diclofenac in pharmaceutical preparations by voltammetry and gas chromatography methods. J Phar Anal 2015;5:153-60.[23] Rouessac F, Rouessac A, Chemical analysis: modern instrumentation methods and techniques. 2nd ed. West Sussex, England: John Wiley and Sons; 2007.

23. Skoog DA, Crouch SR, Holler FJ. Principles of instrumental analysis. 6th ed. Belmont, Australia: Thomson Higher Education; 2007.

24. Stuart B, Infrared spectroscopy: fundamentals and application. West Sussex, England: John Wiley and Sons; 2004.

25. International Conference of Harmonization, Q2 Validation of analytical procedures: text and methodology international conference on harmonization of technical requirements for registration of pharmaceutical for human use, ICH Harmonized Tripartite Guideline, Canada, 2005.

26. Ahuja S, Dong MW. Handbook of pharmaceutical analysis by HPLC. New York, United States: Elsevier Academic Press; 2005.

27. Chan C. Analytical method validation and instrument performance verification. Toronto, Canada: John Wiley and Sons; 2004.

28. Ehmer J, Miller JH. Method validation in pharmaceutical analysis: a guide to best practice. Weinheim, Germany: Wiley-VCH; 2005.

29. Shabir GA. Step-by-Step analytical methods validation and protocol in the quality system compliance industry. In: Analytical Methods Validation. Institute of Validation Technology Duluth; 2006.

30. Shrivastava A, Vipin BG. Methods for the determination of LOD and limit of quantitation of the analytical methods. Chron Young Sci 2011;29:21-5.

31. Nugrahani I, Citra K, Determination of thiamine $\mathrm{HCl}$ (vitamin B1) and pyridoxine $\mathrm{HCl}$ (vitamin B6) content in tablet by FTIR. Int J Pharm Pharm Sci 2016;8:257-64.

32. Nugrahani I, Musaddah MV. Development and validation analysis of acyclovir tablet content determination method using FTIR. Int J App Pharm 2016;8:43-7.

33. Hoang VD, Ly DTH,Tho NH, Nguyen HMT. UV Spectrophotometric simultaneous determination of paracetamol and ibuprofen in combined tablets by derivative and wavelet transforms. Sci World J 2014;:1-13.

34. Lotfy HM. Absorbance subtraction and amplitude modulation as novel spectrophotometric methods for the analysis of binary mixtures. Int J Pharm Pharm Sci 2013;6:735-41.

35. Khveshchuk PF, Rudakova AV. Use of derivative spectrofluorometry in the analysis of ajmaline in drug dosage forms. Pharm Chem J 1995;29:796-98. 